\title{
Progress on the protective effects of maternal fatty acid supplementation on infant asthma risk: a narrative review
}

\author{
Peng $\mathrm{Xu}^{1}$, Zheng Wang ${ }^{1}$, Jie $\mathrm{Li}^{2}$ \\ ${ }^{1}$ College of Bioscience and Biotechnology, Hunan Agricultural University, Changsha, China; ${ }^{2}$ Key Laboratory of Shenzhen Respiratory Disease, \\ Shenzhen Institute of Respiratory Disease, Shenzhen People's Hospital (The First Affiliated Hospital of Southern University of Science and \\ Technology, The Second Clinical Medical College of Jinan University), Shenzhen, China \\ Contributions: (I) Conception and design: Z Wang, J Li; (II) Administrative support: Z Wang, J Li; (III) Provision of study materials or patients: All \\ authors; (IV) Collection and assembly of data: P Xu; (V) Data analysis and interpretation: P Xu; (VI) Manuscript writing: All authors; (VII) Final \\ approval of manuscript: All authors. \\ Correspondence to: Jie Li. Key Laboratory of Shenzhen Respiratory Disease, Shenzhen Institute of Respiratory Disease, Shenzhen People's Hospital \\ (The First Affiliated Hospital of Southern University of Science and Technology, The Second Clinical Medical College of Jinan University), \\ Shenzhen, China. Email: ljszry2018@126.com; Zheng Wang. College of Bioscience and Biotechnology, Hunan Agricultural University, Changsha, \\ China. Email: wz8918@163.com.
}

\begin{abstract}
Asthma is a heterogeneous disease characterized by chronic airway inflammation, and involves a variety of cells and cellular components, which genetic and environmental factors play an important role in the pathogenesis of asthma. It usually occurs in infancy, and epidemiological studies have shown that maternal nutrition during pregnancy is related to the occurrence of asthma in childhood. Fatty acids (FA) are carboxylic acids with different amounts of carbons. Based on the differences between saturated and unsaturated hydrocarbon chains, it can be divided into three categories: saturated fatty acid (SFA, no double bonds between them), monounsaturated fatty acid (MUFA, one double bond), and polyunsaturated fatty acid (PUFA, multiple double bonds). Excessive intake of SFA is the main cause of elevated blood cholesterol, triglyceride, and low-density lipoprotein cholesterol (LDL-C), which leads to arterial lumen stenosis and atherosclerosis, and increases the risk of coronary heart disease. MUFA has hypoglycemic, lipid-lowering, cholesterol-lowering, and antithrombotic effects. SFAs and MUFAs can increase airway inflammation and promote the development of asthma. However, the correlation between maternal SFA and MUFA intake and infant asthma risk has not been reported. The most widely studied PUFA are N-3 PUFA and N-6 PUFA, which mainly derived from vegetable oil, fish oil, and microorganism. As an important component of membrane phospholipids, PUFA can play an immunomodulatory role by affecting the production of eicosanoids, cell membrane fluidity, and gene expression. Maternal intake of PUFAs, especially N-3 PUFAs during pregnancy, can reduce the risk of infant asthma by regulating Th1/Th2 cytokines and immune responses, but a few studies are still controversial. Therefore, large-scale multicenter randomized controlled clinical trials are still warranted to further verify the efficacy of N-3 PUFAs on asthma.
\end{abstract}

Keywords: Asthma; fatty acids; maternal supplementation; N-3 polyunsaturated fatty acids

Submitted Dec 14, 2020. Accepted for publication Feb 04, 2021.

doi: 10.21037/apm-21-88

View this article at: http://dx.doi.org/10.21037/apm-21-88

\section{Introduction}

Asthma is a chronic airway inflammatory disease involving a variety of inflammatory cells and cytokines, and is characterized by airflow limitation and airway hyperresponsiveness (1). Asthma is a common chronic respiratory disease in children, and is listed as one of the four refractory diseases by the World Health Organization (WHO). According to the WHO, the incidence rate 


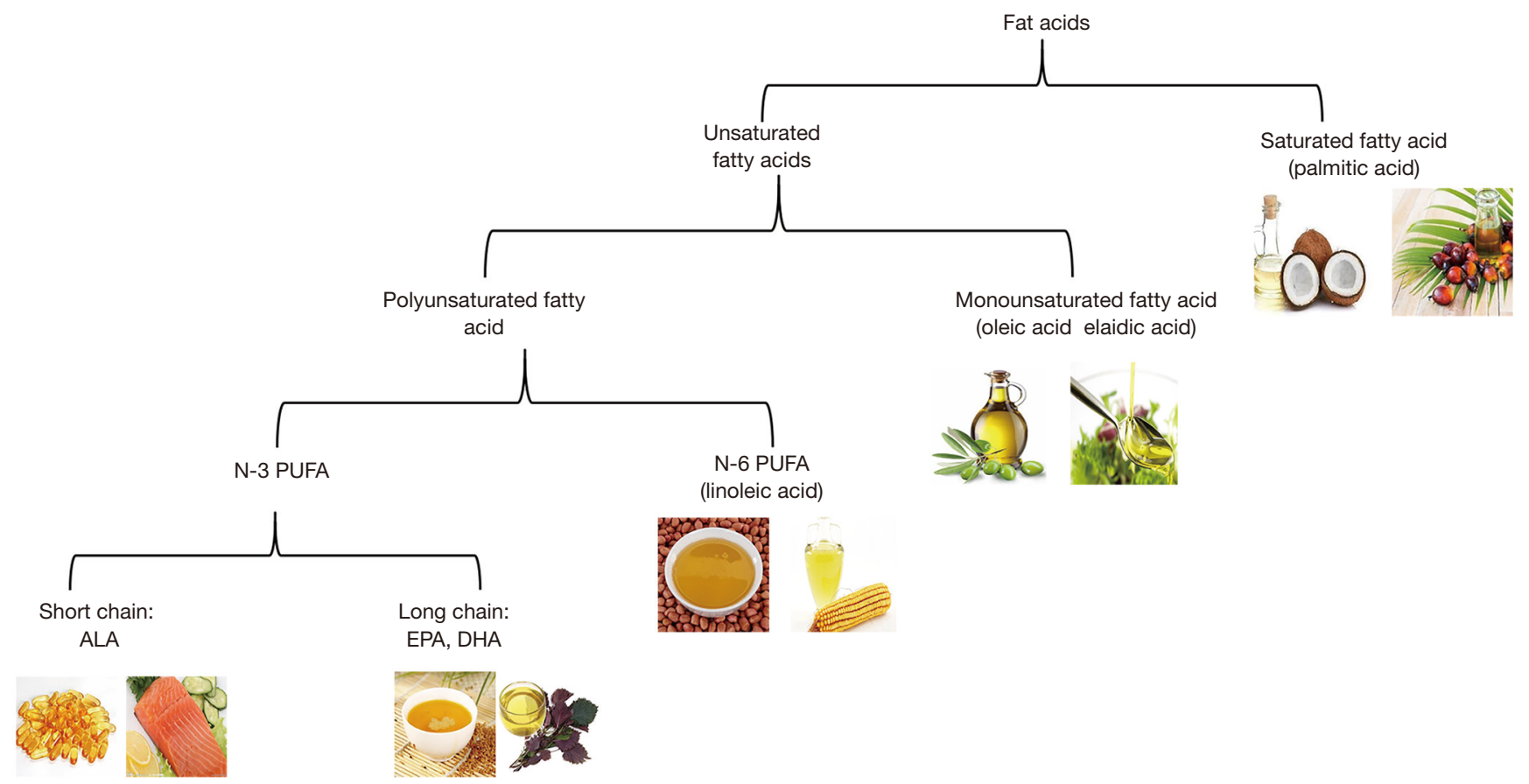

Figure 1 Classification of fatty acids.

of childhood asthma is increasing year by year. By 2025, 100 million children worldwide will suffer from asthma (2). In recent years, it has been recognized that asthma is a heterogeneous disease, and genetic and environmental factors take part in the pathogenesis of asthma $(3,4)$. Epidemiological studies have also shown that maternal nutrition during pregnancy is related to the occurrence of asthma during childhood (5-7). Numerous studies have shown that fatty acids play an important role in asthma. However, there is still a lack of systematic review on maternal fatty acid supplementation on infant asthma risk, and some of the conclusions are controversial.

Fatty acids are compounds composed of carbon, hydrogen, and oxygen. As shown in Figure 1, based on the differences between saturated and unsaturated hydrocarbon chains, they can be divided into three categories: saturated fatty acid (SFA, no double bonds between them), monounsaturated fatty acid (MUFA, one double bond), and polyunsaturated fatty acid (PUFA, multiple double bonds) (8). SFAs generally include caprylic acid, decanoic acid, lauric acid, myristic acid, palmitic acid, stearic acid, and arachidonic acid (AA), amongst others. This type of fatty acid is mainly found in the fat of cattle, sheep, pigs, and other animals, and a few plants such as coconut oil, cocoa oil, and palm oil. Excessive intake of SFA is the main cause of elevated blood cholesterol, triglycerides, and lowdensity lipoprotein cholesterol (LDL-C), which leads to arterial lumen stenosis and atherosclerosis, and increases the risk of coronary heart disease $(9,10)$. MUFAs, including myristic acid, palmitoleic acid, oleic acid, and ricinoleic acid, are mainly derived from animal and plant fats, and are more important in human nutrition and physiology. Relevant studies have shown that MUFAs have hypoglycemic, lipidlowering, cholesterol-lowering, and antithrombotic effects $(11,12)$. PUFAs are mainly derived from vegetable oil, fish oil, and microorganisms. The most widely studied PUFAs are N-3 PUFAs [mainly including linolenic acid, docosahexaenoic acid (DHA), and eicosapentaenoic acid (EPA)] and N-6 PUFAs (mainly including linoleic acid, gamma-linolenic acid, and AA). Like vitamins and minerals, they are essential to the human body, and a lack of them can easily lead to disorders of vital organs such as the heart and the brain $(13,14)$. The accretion of PUFAs, especially docosahexaenoic acid (DHA) in membranes of the central nervous system is required for the optimum development of retina and brain functions (15). The maternal intake of n-3 PUFA during pregnancy and lactation is also critical, since the n-3 PUFA are provided during perinatal development through placental transfer and maternal milk, which determines the DHA status of the newborn 


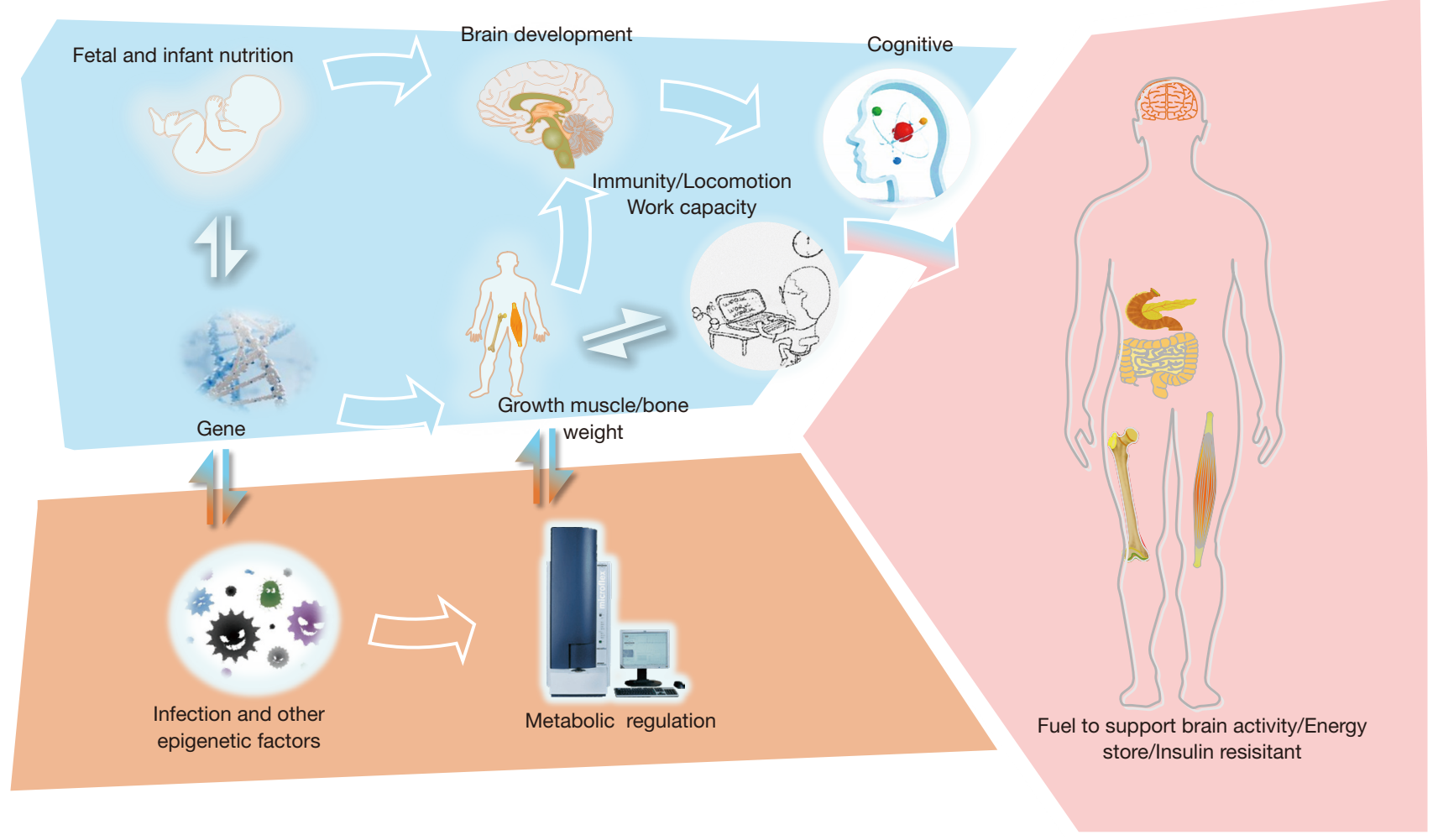

Figure 2 The developmental origins of health and disease theory.

and consequently influence on post-natal development of brain and visual functions $(16,17)$. In this review, we will pay special attention to dietary fatty acids, and review the impact of maternal fatty acid intake on childhood asthma, in order to provide new ideas for the prevention of childhood asthma. We present the following article in accordance with the Narrative Review reporting checklist (available at http:// dx.doi.org/10.21037/apm-21-88).

\section{The effects of maternal fatty acid supplementation on infant asthma}

\section{Theoretical basis}

Infant asthma is the result of the interactions between genetic susceptibility and multiple environmental factors (18). Although genetic susceptibility is considered to be the main cause of infant asthma, the genetic sequence is less likely to change significantly in a short time. The incidence rate of infant asthma has increased rapidly in recent years (19). Therefore, it is speculated that the increased incidence of infant asthma is largely due to physical, chemical, biological, dietary, and other environmental factors. Early life is a special period when immune system development is at its peak. As the immune system is not yet mature, it is vulnerable to the effects of environmental conditions, thus inducing asthma (20). Figure 2 shows the theory of 'developmental origins of health and disease (DOHaD)', which holds that the intrauterine and infant stages are the key window periods for development, which will affect the occurrence of diseases in adulthood $(21,22)$. Dietary nutrition in early life is considered to be an important influential environmental factor. Malnutrition or imbalance may cause fetuses in the sensitive period to adaptively adjust their metabolism and the structure of tissues and organs, thus laying the foundation for future diseases $(23,24)$. For example, compared to mothers with low vitamin D intake during pregnancy, children of mothers with high vitamin D intake had significantly lower asthma recurrence rates in early childhood $(5,25)$. In 1997, Black et al. proposed the hypothesis that the increase in asthma prevalence in recent years was related to the changes in dietary fat intake, 
especially the increase in N-6 PUFAs and the decrease in N-3 PUFAs (26). The levels of N-6 and N-3 PUFAs in breast milk 3 months after delivery were positively and negatively correlated with the incidence of asthma in 14-year-old children, respectively (27). The ratio of N-3 to N-6 PUFAs in breast milk was also negatively correlated with the occurrence of allergic persistent symptoms such as asthma in children (28).

\section{The mechanism of fatty acid regulation in infant asthma}

Common infant allergic diseases include eczema, bronchial asthma, allergic rhinitis, and conjunctivitis. In terms of the molecular and cytological mechanisms of allergic diseases, classical allergic reactions are mediated by $\operatorname{IgE}$ and $\mathrm{T}$ helper cells $(29,30)$. Airway tissues and cells of asthmatic patients are mainly characterized by a large number of eosinophils infiltrating and secreting $\operatorname{IgE}$, therefore the levels of $\operatorname{IgE}$ in most asthmatic patients are high (31). The functional imbalance of T helper cell type 1 and 2 (Th1/Th2) subsets, especially Th2 dominant responses, plays an important role in eosinophil chemotaxis and activation and $\mathrm{IgE}$ secretion by B lymphocytes $(32,33)$.

Among the many dietary and nutritional factors, PUFA intake in early life is an important factor for asthma. It has been found that PUFAs, as important components of membrane phospholipids, can play an immunomodulatory role by affecting the production of eicosanoids, cell membrane fluidity, and gene expression (34-36). In particular, the n-3 PUFA (ALA, EPA, DHA) may present anti-inflammatory capabilities by inhibition of transcriptional factor $\mathrm{NF}-\mathrm{\kappa B}$ and subsequent decrease in proinflammatory cytokines production, thereby preventing the development of asthma $(37,38)$. N-6 PUFA mainly refers to linoleic acid derived from vegetable oil, which is a precursor of the pro-inflammatory substance arachidonic acid (AA) (39). AA can promote the expression of prostaglandin E2 (PGE2) and leukotriene B4 (LTB4) (40). Both PGE2 and LTB4 play important roles in anaphylaxis by enhancing inflammation and $\mathrm{IgE}$ responses. In addition, PGE2 can reduce the secretion of IL-2, thereby decreasing the proportion of Th1/Th2 cytokines, and promoting infant asthma and other allergic diseases $(41,42)$. In contrast, growing evidence has shown that N-3 PUFAs may have anti-inflammatory properties and regulate immune responses. They can strengthen or inhibit multiple links in the classic Th1/Th2 allergic reaction process by changing cell membrane fluidity, cell signal transduction, and gene transcription, thus affecting the occurrence of allergic diseases (43). The protective mechanisms of N-3 PUFAs have also been verified in clinical trials. Dunstan et al. found that supplementation with fish oil rich in N-3 PUFA during pregnancy could increase the levels of EPA and DHA, and decrease the secretion of the Th2 cytokine IL13 in neonates, thus reducing the activation of $\mathrm{B}$ cells in the process of asthma (44). Prescott et al. studied the effects of N-3 PUFA intervention during pregnancy on neutrophilic granulocyte function in neonates and found reduced secretion of LTB4 and the pro-inflammatory factor IL-6 in lipopolysaccharide-stimulated monocytes from neonates in the intervention group, indicating that N-3 PUFA can affect the development of the immune system in early life (45). It has also been found in clinical studies, maternal fish oil supplementation resulted in a remarkable increase in n-3 PUFA levels in neonatal erythrocyte membranes. Neonates whose mothers had fish oil supplementation had meaningfully lower plasma IL-13 (44). Lee et al. investigated the effect of the pregnancy supplementation with $400 \mathrm{mg}$ DHA per day from 18 to 22 weeks of pregnancy and found no change in promoter methylation levels in cord blood leucocytes for the genes analyzed. However, an association between the promoter methylation levels of interferon-gamma and IL-13 was adjusted by $\mathrm{n}-3$ PUFA supplementation in the maternal only smoking group (46).

In addition to being immune regulatory, N-3 PUFA intake have been related to microbial changes in both human observational studies and murine intervention models. Both early life bacterial composition and specific bacterial genera in the neonatal airways have been associated with increased disease risk later in life $(47,48)$. Hjelmsø et al. found that maternal N-3 PUFA and vitamin D intake affect the infant airways. Changes in overall beta multiplicity are observed, which in turn associates with a change in immune mediator profile. In addition, airway microbial maturation and the relative abundance of specific bacterial genera are altered (49).

During pregnancy and/or lactation, the maternal consumption of n-3 and n-6 FA can also contribute to brain development and may be refer to the determination of body composition, affect the status of lipid tissues and regulate metabolic pathways result in changes in the risk for developing diseases in adults, such as obesity, diabetes, cancer and cardiovascular or asthma (50-52). 


\section{Clinical research}

At present, N-3 PUFAs are the most widely studied PUFAs in clinical practice. N-3 PUFAs, mainly including $\alpha$-linolenic acid (ALA) from green vegetables, and EPA and DHA from fish fats, can modulate the risk of asthma (53). Romieu et al. evaluated the impact of fish consumption during pregnancy on the incidence of asthma and found that children's risk of developing asthma by age 6 was decreased by $35.1 \%$ when the fish intake of mothers increased from 1 to 2.5 times/ week during pregnancy, suggesting a protective effect of fish intake during pregnancy on the risk of atopy-related outcomes (54). In another randomized controlled trial, mothers in the experimental group were given fish oil (2.7 $\mathrm{g}$ N-3 PUFA/d) from the 30th week of pregnancy, while olive oil was given to the control group. After 16 years of followup, the asthma risk of the offspring in the experimental group was $87 \%$ lower than that in the control group (55). Bisgaard et al. found that high dose fish oil supplementation in late pregnancy significantly reduced the risk of persistent wheezing or asthma in offspring under 5 years of age, and reduced their risk of lower respiratory tract infection by approximately 7\% (56). A randomized controlled study on whether fish oil supplementation during pregnancy reduced the risk of asthma in adult offspring starting in 1990 and lasting for 24 years has shown that fish oil supplementation during pregnancy may have the potential for longterm asthma prevention in offspring (57). Dunstan et al. demonstrated in an intervention study that supplementing with N-3 PUFA in early pregnancy could reduce the risk of childhood asthma (58). It is worth mentioning that maintaining the balance between N-3 PUFAs and N-6 PUFAs is of great significance due to their different roles in regulating immune and inflammatory responses. The optimal ratio of $\mathrm{N}-6 / \mathrm{N}-3$ PUFAs in the daily diet is $4 / 1$ recommended by Japanese experts or 2.3/1 recommended by American experts (59).

\section{The dispute}

Although many studies have shown that N-3 PUFA supplementation during pregnancy can reduce the risk of asthma in children, some studies have shown contrasting results. According to the follow-up investigation of 121 mother-child groups across three regions, the types and proportions of PUFA intake were different due to the diverse product consumption patterns of pregnant women in the three regions. However, it was found that PUFA in breast milk and umbilical cord blood was not associated with the incidence of total allergic diseases (eczema, measles, and asthma) in infants within 6 months. A prospective cohort study conducted in the Netherlands showed that shellfish consumption in the diet of mothers during pregnancy was associated with a higher risk of wheezing and eczema in children, the consumption of fatty fish was associated with a higher risk of eczema, and the consumption of low-fat fish was not associated with wheezing or eczema in children.

\section{Summary}

Numerous studies have shown that N-3 PUFA plays an important role in asthma. The administration of N-3 PUFA for adjuvant therapy of asthma and its potential for primary asthma prevention are likely to be effective and feasible. However, it is important to note that various factors, such as inconsistency in the quality and purity of test samples and the characteristics of the research subjects (such as age and nationality), may affect the results of clinical studies. Furthermore, the effects of the dose of N-3 PUFA and its ratio to N-6 PUFA on asthma need to be further clarified. Large-scale multicenter randomized controlled clinical trials are still warranted to further verify the efficacy of $\mathrm{N}-3$ PUFAs on asthma. Finally, current evidence also suggests a protective effect of maternal intake of vitamin $\mathrm{D}$, vitamin $\mathrm{E}$, zinc et al. against childhood asthma. Therefore, the combined intake of multiple nutrients may play a more important role in the prevention of neonatal asthma.

\section{Acknowledgments}

Funding: This work was supported by the Key Laboratory of Shenzhen Respiratory Disease (ZDSYS201504301616234), the Hunan Provincial Natural Science Foundation (2019JJ40134), the Scientific Research Fund of Hunan Provincial Education Department (18A098), and the Hunan Provincial Graduate Research and Innovation Project (CX2018B404). This work also was supported by special funding for high-level disciplines from the Shenzhen Institute of Respiratory Diseases.

\section{Footnote}

Reporting Checklist: The authors have completed the Narrative Review reporting checklist. Available at http:// dx.doi.org/10.21037/apm-21-88 
Conflicts of Interest: All authors have completed the ICMJE uniform disclosure form (available at http://dx.doi. org/10.21037/apm-21-88). The authors have no conflicts of interest to declare.

Ethical Statement: The authors are accountable for all aspects of the work in ensuring that questions related to the accuracy or integrity of any part of the work are appropriately investigated and resolved.

Open Access Statement: This is an Open Access article distributed in accordance with the Creative Commons Attribution-NonCommercial-NoDerivs 4.0 International License (CC BY-NC-ND 4.0), which permits the noncommercial replication and distribution of the article with the strict proviso that no changes or edits are made and the original work is properly cited (including links to both the formal publication through the relevant DOI and the license). See: https://creativecommons.org/licenses/by-nc-nd/4.0/.

\section{References}

1. Chu DK, Al-Garawi A, Llop-Guevara A, et al. Therapeutic potential of anti-IL-6 therapies for granulocytic airway inflammation in asthma. Allergy Asthma Clin Immunol 2015;11:14.

2. Puranitee P, Kamchaisatian W, Manuyakorn W, et al. Direct medical cost of Thai pediatric asthma management: a pilot study. Asian Pac J Allergy Immunol 2015;33:296-300.

3. Deliu M, Yavuz TS, Sperrin M, et al. Features of asthma which provide meaningful insights for understanding the disease heterogeneity. Clin Exp Allergy 2018;48:39-47.

4. Modena BD, Bleecker ER, Busse WW, et al. Gene Expression Correlated with Severe Asthma Characteristics Reveals Heterogeneous Mechanisms of Severe Disease. Am J Respir Crit Care Med 2017;195:1449-63.

5. Beckhaus AA, Garcia-Marcos L, Forno E, et al. Maternal nutrition during pregnancy and risk of asthma, wheeze, and atopic diseases during childhood: a systematic review and meta-analysis. Allergy 2015;70:1588-604.

6. Lee-Sarwar K, Litonjua AA. As You Eat It:Effects of Prenatal Nutrition on Asthma. J Allergy Clin Immunol Pract 2018;6:711-8.

7. Song H, Yang L, Jia C. Maternal vitamin D status during pregnancy and risk of childhood asthma:A meta-analysis of prospective studies. Mol Nutr Food Res 2017;61. doi: 10.1002/mnfr.201600657.
8. Sui YH, Luo WJ, Xu QY, et al. Dietary saturated fatty acid and polyunsaturated fatty acid oppositely affect hepatic NOD-like receptor protein 3 inflammasome through regulating nuclear factor-kappa B activation. World J Gastroenterol 2016;22:2533-44.

9. Kleber ME, Delgado GE, Dawczynski C, et al. Saturated fatty acids and mortality in patients referred for coronary angiography-The Ludwigshafen Risk and Cardiovascular Health study. J Clin Lipidol 2018;12:455-463.e3.

10. Dias CB, Wood LG, Garg ML. Effects of dietary saturated and n-6 polyunsaturated fatty acids on the incorporation of long-chain n-3 polyunsaturated fatty acids into blood lipids. Eur J Clin Nutr 2016;70:812-8.

11. Qian F, Hu FB. Response to Comment on Qian et al. Metabolic Effects of Monounsaturated Fatty AcidEnriched Diets Compared With Carbohydrate or Polyunsaturated Fatty Acid-Enriched Diets in Patients With Type 2 Diabetes: A Systematic Review and Metaanalysis of Randomized Controlled Trials. Diabetes Care 2016;39:1448-1457. Diabetes Care 2016;39:e205.

12. Grosso G, Estruch R. Nut consumption and age-related disease. Maturitas 2016;84:11-6.

13. Choi J, Yin T, Shinozaki K, et al. Comprehensive analysis of phospholipids in the brain, heart, kidney, and liver: brain phospholipids are least enriched with polyunsaturated fatty acids. Mol Cell Biochem 2018;442:187-201.

14. Bos DJ, van Montfort SJ, Oranje B, et al. Effects of omega-3 polyunsaturated fatty acids on human brain morphology and function: What is the evidence? Eur Neuropsychopharmacol 2016;26:546-61.

15. Lauritzen L, Brambilla P, Mazzocchi A, et al. DHA effects in brain development and function. Nutrients 2016;8:6-22.

16. Wysoczański T, Sokoła-Wysoczańska E, Pękala J, et al. Omega-3 Fatty Acids and their Role in Central Nervous System - A Review. Curr Med Chem 2016;23:816-31.

17. Hoare S, Lithander F, Van Der Mei I, et al. Higher intake of omega-3 polyunsaturated fatty acids is associated with a decreased risk of a first clinical diagnosis of central nervous system demyelination: Results from the Ausimmune Study. Mult Scler 2016;22:884-92.

18. Lee JU, Kim JD, Park CS. Gene-Environment Interactions in Asthma: Genetic and Epigenetic Effects. Yonsei Med J 2015;56:877-86.

19. Overton NL, Simpson A, Bowyer P, et al. Genetic susceptibility to severe asthma with fungal sensitization. Int J Immunogenet 2017;44:93-106.

20. Rosa MJ, Lee AG, Wright RJ. Evidence establishing a link between prenatal and early-life stress and asthma 
development. Curr Opin Allergy Clin Immunol 2018;18:148-58.

21. Gluckman PD, Hanson MA, Mitchell MD. Developmental origins of health and disease: reducing the burden of chronic disease in the next generation. Genome Med 2010;2:14.

22. Heindel JJ, Balbus J, Birnbaum L, et al. Developmental Origins of Health and Disease: Integrating Environmental Influences. Endocrinology 2015;156:3416-21.

23. Larson-Nath C, Goday P. Malnutrition in children with chronic disease. Nutr Clin Pract 2019;34:349-58.

24. Wells JC, Sawaya AL, Wibaek R, et al. The double burden of malnutrition: aetiological pathways and consequences for health. Lancet 2020;395:75-88.

25. Camargo CA Jr, Rifas-Shiman SL, Litonjua AA, et al. Maternal intake of vitamin D during pregnancy and risk of recurrent wheeze in children at $3 \mathrm{y}$ of age. Am J Clin Nutr 2007;85:788-95.

26. Black PN, Sharpe S. Dietary fat and asthma: is there a connection? Eur Respir J 1997;10:6-12.

27. van Elten TM, van Rossem L, Wijga AH, et al. Breast milk fatty acid composition has a long-term effect on the risk of asthma, eczema, and sensitization. Allergy 2015;70:1468-76.

28. Wijga AH, van Houwelingen AC, Kerkhof M, et al. Breast milk fatty acids and allergic disease in preschool children: the Prevention and Incidence of Asthma and Mite Allergy birth cohort study. J Allergy Clin Immunol 2006;117:440-7.

29. Woodfolk JA, Commins SP, Schuyler AJ, et al. Allergens, sources, particles, and molecules: Why do we make $\mathrm{IgE}$ responses? Allergol Int 2015;64:295-303.

30. McFadden JP, Thyssen JP, Basketter DA, et al. T helper cell 2 immune skewing in pregnancy/early life: chemical exposure and the development of atopic disease and allergy. Br J Dermatol 2015;172:584-91.

31. Heeringa JJ, Rijvers L, Arends NJ, et al. IgE-expressing memory B cells and plasmablasts are increased in blood of children with asthma, food allergy, and atopic dermatitis. Allergy 2018;73:1331-6.

32. Maes T, Cobos FA, Schleich F, et al. Asthma inflammatory phenotypes show differential microRNA expression in sputum. J Allergy Clin Immunol 2016;137:1433-46.

33. Taylor SL, Leong LEX, Choo JM, et al. Inflammatory phenotypes in patients with severe asthma are associated with distinct airway microbiology. J Allergy Clin Immunol 2018;141:94-103.e15.

34. Shaikh SR, Kinnun JJ, Leng X, et al. How polyunsaturated fatty acids modify molecular organization in membranes: insight from NMR studies of model systems. Biochim Biophys Acta 2015;1848:211-9.

35. Liu Y, Zu L, Cai W, et al. Metabolomics revealed decreased level of omega-3 PUFA-derived protective eicosanoids in pregnant women with pre-eclampsia. Clin Exp Pharmacol Physiol 2019;46:705-10.

36. Kamat SG, Roy R. Evaluation of the effect of n-3 PUFArich dietary fish oils on lipid profile and membrane fluidity in alloxan-induced diabetic mice (Mus musculus). Mol Cell Biochem 2016;416:117-29.

37. Wang T, Yang B, Ji R, et al. Omega-3 polyunsaturated fatty acids alleviate hepatic steatosis-induced inflammation through Sirt1-mediated nuclear translocation of NF- $\mathrm{kB}$ p 65 subunit in hepatocytes of large yellow croaker (Larmichthys crocea). Fish Shellfish Immunol 2017;71:76-82.

38. Panda L, Gheware A, Rehman R, et al. Linoleic acid metabolite leads to steroid resistant asthma features partially through NF-кB. Sci Rep 2017;7:1-11.

39. Innes JK, Calder PC. Omega-6 fatty acids and inflammation. Prostaglandins Leukot Essent Fatty Acids 2018;132:41-8.

40. Su HH, Lin HT, Suen JL, et al. Aryl hydrocarbon receptor-ligand axis mediates pulmonary fibroblast migration and differentiation through increased arachidonic acid metabolism. Toxicology 2016;370:116-26.

41. Kaisar MMM, Ritter M, Del Fresno C, et al. Dectin-1/2induced autocrine PGE2 signaling licenses dendritic cells to prime Th2 responses. PLoS Biol 2018;16:e2005504.

42. Chkhaidze I, Zirakishvili D, Shavshvishvili N, et al. Prognostic value of TH1/TH2 cytokines in infants with wheezing in a three year follow-up study. Pneumonol Alergol Pol 2016;84:144-50.

43. Yessoufou A, Nekoua MP, Gbankoto A, et al. Beneficial effects of omega-3 polyunsaturated Fatty acids in gestational diabetes: consequences in macrosomia and adulthood obesity. J Diabetes Res 2015;2015:731434.

44. Dunstan JA, Mori TA, Barden A, et al. Maternal fish oil supplementation in pregnancy reduces interleukin-13 levels in cord blood of infants at high risk of atopy. Clin Exp Allergy 2003;33:442-8.

45. Prescott SL, Barden AE, Mori TA, et al. Maternal fish oil supplementation in pregnancy modifies neonatal leukotriene production by cord-blood-derived neutrophils. Clin Sci (Lond) 2007;113:409-416.

46. Lee HS, Barraza-Villarreal A, Hernandez-Vargas H, et al. Modulation of DNA methylation states and infant immune 
system by dietary supplementation with $\omega-3$ PUFA during pregnancy in an intervention study. Am J Clin Nutr 2013;98:480-7.

47. Bisgaard H, Hermansen M N, Buchvald F, et al. Childhood asthma after bacterial colonization of the airway in neonates. N Engl J Med 2007;357:1487-95.

48. von Linstow ML, Schønning K, Hoegh AM, et al. Neonatal airway colonization is associated with troublesome lung symptoms in infants. Am J Respir Crit Care Med 2013;188:1041-2.

49. Hjelmsø MH, Shah SA, Thorsen J, et al. Prenatal dietary supplements influence the infant airway microbiota in a randomized factorial clinical trial. Nat Commun 2020;11:426.

50. Griffiths PS, Walton C, Samsell L, et al. Maternal highfat hypercaloric diet during pregnancy results in persistent metabolic and respiratory abnormalities in offspring. Pediatr Res 2016;79:278-86.

51. Forno E, Celedón JC. The effect of obesity, weight gain, and weight loss on asthma inception and control. Curr Opin Allergy Clin Immunol 2017;17:123-30.

52. Wang S, Tang K, Lu Y, et al. Revealing the role of glycerophospholipid metabolism in asthma through plasma lipidomics. Clin Chim Acta 2021;513:34-42.

53. Kim EK, Ju SY. Asthma and Dietary Intake of Fish, Seaweeds, and Fatty Acids in Korean Adults. Nutrients

Cite this article as: $\mathrm{Xu} \mathrm{P}$, Wang $\mathrm{Z}, \mathrm{Li}$ J. Progress on the protective effects of maternal fatty acid supplementation on infant asthma risk: a narrative review. Ann Palliat Med 2021;10(2):2323-2330. doi: 10.21037/apm-21-88
2019;11:2187.

54. Romieu I, Torrent M, Garcia-Esteban R, et al. Maternal fish intake during pregnancy and atopy and asthma in infancy. Clin Exp Allergy 2007;37:518-25.

55. Olsen SF, Osterdal ML, Salvig JD, et al. Fish oil intake compared with olive oil intake in late pregnancy and asthma in the offspring: $16 \mathrm{y}$ of registry-based followup from a randomized controlled trial. Am J Clin Nutr 2008;88:167-75.

56. Bisgaard H, Stokholm J, Chawes BL, et al. Fish OilDerived Fatty Acids in Pregnancy and Wheeze and Asthma in Offspring. N Engl J Med 2016;375:2530-9.

57. Hansen S, Strom M, Maslova E, et al. Fish oil supplementation during pregnancy and allergic respiratory disease in the adult offspring. J Allergy Clin Immunol 2017;139:104-111.e4.

58. Dunstan JA, Mori TA, Barden A, et al. Fish oil supplementation in pregnancy modifies neonatal allergenspecific immune responses and clinical outcomes in infants at high risk of atopy: a randomized, controlled trial. J Allergy Clin Immunol 2003;112:1178-84.

59. Demmelmair H, Koletzko B. Importance of fatty acids in the perinatal period. World Rev Nutr Diet 2015;112:31-47.

(English Language Editor: C. Betlazar-Maseh) 